\title{
Publisher's Note: Lessons learned from positron-electron project low level rf and longitudinal feedback \\ [Phys. Rev. ST Accel. Beams 13, 052802 (2010)]
}

\author{
J. Fox, T. Mastorides, C. Rivetta, D. Van Winkle, and D. Teytelman \\ (Received 26 June 2010; published 12 July 2010)
}

DOI: 10.1103/PhysRevSTAB.13.079901

PACS numbers: 29.27.Bd, 29.20.db, 99.10.Fg

This work was published on 19 May 2010 with an omission in the Acknowledgments. "This work was supported by the U.S. Department of Energy under Contract No. DE-AC02-76SF00515." has been added to the Acknowledgments section online as of 30 June 2010. 